\title{
Futures we are in (conference report)
}

\author{
Michael van Beinum and Martin TuRner, Royal Edinburgh Hospital, Edinburgh
}

On 1 March 1989 over 90 trainees attended a day conference organised by the Scottish section of the CTC at the Royal Edinburgh Hospital. In the morning Sir James Fraser gave a surgeon's view of psychiatry in Scotland. This was followed by two different perspectives of new ways of working in the NHS, both with a strong community commitment. It is clear that in future community psychiatry will be integral to all psychiatric practice and the training of psychiatrists should reflect this. For instance, part of training at SR level should include experience of setting up communty initiatives. The afternoon session discussed a management perspective of changes in the NHS and the MRCPsych. exam, Part II.

We focus on the contribution of Sir James Fraser, chairman of the psychiatric sub-committee of the Gavin Shaw report. The Shaw report looked at the imbalance of doctors in training and manpower requirements, looking in detail at the staffing of every unit in each speciality. A team of senior clinicians with a junior representative visited every major unit in Scotland. It is unfortunate that Achieving a Balance, which was a paper exercise, is to be implemented and Shaw, which recommended consultant expansion of roughly $30 \%$, is not.

Many difficulties in making an assessment of hospital services were encountered. Base line facts, such as the current staffing levels and patient numbers, proved to be impossible to obtain. Nobody seemed to know how many doctors were in training in any given region at any one time or what the norms of the psychiatric service were in any given region. There was, for instance, an enormous regional variation in social work departments and their attitudes to local psychiatric services.

Sir James made a number of points. First, there is a restriction of resources available due to competition from the acute specialties, and there is no doubt that the psychiatric service is underfunded and understaffed. There was a problem in the relationship of peripheral units to regional training centres. There were many first-class hospitals but few were able to provide an adequate variety of training on their own; they needed to be part of a regionally-organised training scheme if they were to gain College approval. Nonetheless, small hospitals often provided a marvellous service to patients. Sir James noted the rapid progress made by some peripheral units in improving standards of care but felt that units without trainees found it unduly difficult to persuade the College to grant approval for SHO/ registrar training. This in turn affected hospital morale and consultant recruitment. Unfortunately, some trainees were reluctant to move from a major teaching hospital to a smaller, more remote, but equally good hospital as part of their training. There was also a reluctance from some consultants to move out to the periphery. In rural areas there were major problems in arranging rotations because of the very considerable distances between hospitals.

Morale was important in providing good patient care. Some training schemes were just too small to achieve a 'critical mass'. They provided all the variety needed, but there were not enough trainees to maintain an enthusiastic training programme. In other schemes, the cause of low morale was harder to pinpoint. Staff felt overworked and understaffed, but the workload was not markedly different from that in equivalent schemes where morale was very good. Where morale was low, the staff were reluctant to discharge patients, leading to an increased workload.

Low morale was countered by a mix of different types of trainees, such as GP and career psychiatrist. Increasingly the care of long-term patients is now being taken over by trained GPs, freeing trainees to concentrate on psychiatry. The quality of the senior consultant(s) in the hospital was seen as being of great importance in determining morale, and hence the quality of training. Interestingly, the very poor quality of the Victorian buildings housing many hospitals was not linked to staff morale or the quality of care of patients. Thus an immediate massive injection of capital investment is not the answer to improving morale and this, Sir James said, was amply demonstrated by the Government's approach to some mental handicap hospitals.

The quality of training is extremely variable in Scotland. Trainees from different schemes in Scotland have very different promotion prospects; one cannot become an SR without training in one of the major training centres. This, together with the College's reluctance to approve newly proposed training schemes, can hamper the development of peripheral units. Regional control of training would also counter the distorting effect of having a few centres of excellence. 